Editorial

\title{
New era of EUJAPA
}

\author{
Pauli Rintala ${ }^{*}$
}

Published: 21 st January 2019

The first year as Editor-in-Chief is behind me. It has been personally challenging, but also educational in many ways. I have been a regular manuscript reviewer for decades, as an Editorial Board member for Adapted Physical Activity Quarterly (APAQ), but being in charge is another angle to the same process. As the editor, you have to make a lot more decisions on several things, such as 'Is the manuscript within the scope of the journal?', 'Who might be the best reviewers for this particular topic?', 'Who do you ask next if the ones you selected decline?' and so on. It is a constant learning process, and at times difficult make correct decisions all the time.

During this past year the journal had to go through the process of changing the journal platform due to disturbances from hackers (Kudlacek, 2018). The new ACTAVIA journal system seems to be working well. Moreover, due to editor transfer, there is a continuous need to find enough finances and manual assistance to handle the publication process, including layout and proofreading phases. We are still searching the most convenient way to do it.

I have been fortunate to have Dr. Kwok $\mathrm{Ng}$ as my assistant editor. He has been an enormous help and many times a vital person to tackle the digital and technical problems we have confronted during this transition. He introduced a ready-made, self-explanatory template for the submitting authors and created a tutorial video to use. Templates are common across many electronically publishing journals and is used to speed up the publication process following acceptance. I want to take this opportunity to thank Kwok for his commitment to improve EUJAPA, and his efforts to help me to succeed in my role as Editor.

Adapted Physical Activity is a very large discipline and spans over several areas of sport and exercise sciences. Additionally, the published research can be quantitative or qualitative in nature, which brings another flavor into the review process. EUJAPA faces the similar challenges to its 'big brother' APAQ as described in the editorial of APAQ's current Editor, Prof. Jeffrey Martin (2017). In addition, EUJAPA is an international journal, which publishes articles in English. There are many non-native speakers of English and there are extra hurdles in finding a proper way of expressing ourselves as authors, reviewers as well as editors.

In spite of the above mentioned challenges, the number of submissions to EUJAPA has been increasing over the years. At the moment we are able to produce good articles and publish two issues per year. I am thankful for all the submitting authors, as well as those reviewers who have made this possible. Many thanks also for the Section Editors, Professors Klavina, Molik and Ferreira for their contributions for EUJAPA. Lastly, my gratitude goes to Dr. Martin Kudlacek for his long-time efforts as past editor for bringing EUJAPA where it is at the moment (see editorial Kudlacek, 2018).

Author affiliations:

1 Faculty of Sport and Health Sciences, University of Jyvaskyla; Pauli.rintala@jyu.fi

* Correspondence: Pauli.rintala@jyu.fi;

\section{References}

Kudlacek, M. (2018). European Journal of Adapted Physical Activity in the second decade. European Journal of Adapted Physical Activity, 11(1):1. doi: 10.5507/euj.2018.007

Martin, J.J. (2017). Your new editor. Adapted Physical Activity Quarterly, 34(2), 97-103. doi: 10.1123/apaq.2017-0047

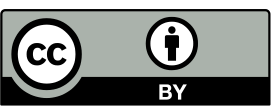
(C) 2018 by the authors. Submitted for possible open access publication under the terms and conditions of the Creative Commons Attribution (CC BY) license (http://creativecommons.org/licenses/by/4.0/). 